\title{
HOW WELL DOES SATELLITE FINE MODE AEROSOL PRODUCT VALIDATE WITH GROUND-BASED MEASUREMENTS FOR MODIS AND HIMAWARI-8?
}

\author{
Jiannan Jin ${ }^{1,2,3}$, Xingchuan Yang ${ }^{3}$, Chen Liang ${ }^{1,2}$, Wenji Zhao ${ }^{3}$, Zhanqing Li $^{1,4}$, Xing Yan ${ }^{1,2 *}$ \\ 1 College of Global Change and Earth System Science, Beijing Normal University, Beijing, China \\ 2 Joint Center for Global Change Studies (JCGCS), Beijing 100875, China \\ 3 College of Resource Environment and Tourism, Capital Normal University, Beijing, China \\ 4 Department of Atmospheric and Oceanic Science, and Earth System Science Interdisciplinary Center, University of Maryland, \\ College Park, Maryland, USA
}

Commission WG III/8

KEY WORDS: MODIS, Himawari-8, AERONET, fine mode aerosol, fine mode fraction

\begin{abstract}
:
Currently, the validation of MODIS and Himawari-8 aerosol products mostly focuses on AOD, but the validation of their fine mode aerosol data is limited. In this paper, 22 AERONET sites in Asia from 2015 to 2016 were selected to validate the MODIS and the Himawari-8 fine aerosol product. In the validation of all the observation data the accuracy of the MODIS fAOD (RMSE is 0.399 and MAE is 0.280) is higher than the Himawari-8 fAOD (RMSE is 0.433 and MAE is 0.293). For the validation of FMF, the accuracy of MODIS FMF (RMSE is 0.520 and MAE is 0.433 ) is higher than the Himawari-8 FMF (RMSE is 0.535 and MAE is 0.438) as well. This research also presents the validation in different AERONET locations. From the all validation results, MODIS retrievals of fine mode aerosol products are better than that of Himawari-8's. However, in comparison with AERONET observations, both MODIS and Himawari- 8 retrievals are underestimated. Therefore, we need to further develop the fine mode aerosol retrieval method to obtain more accurate fine mode aerosol product by satellite.
\end{abstract}

\section{INTRODUCTION}

Aerosols are known to have a substantial effect on the Earth's energy balance and climate change. The fine mode aerosols are particles with a range of 0.1 to 0.25 microns. For the fine mode aerosol, its optical depth (fAOD) is one of the most important parameters. $\mathrm{fAOD}$ is an important factor to determine the climate effect of the fine mode aerosol. It can provide visibility and key information on the impact of radiation balance. Therefore, the study of the fAOD is helpful to understand the atmospheric conditions and is significant for monitoring and controlling the atmospheric pollution (Yan et al., 2017b).

At present, there are currently two common ways to obtain data regarding fAOD: one is from ground-based measurements such as the Aerosol Robotic Network (AERONET) and the other is from space-borne Observations. AERONET is a globally distributed network of Sun photometers that measure directly transmitted solar light during daylight hours (Holben et al.,1998). Many studies have shown that AERONET can provide highly accurate fAOD data. However, AERONET is based on point measurements and has much smaller spatial coverage than the satellite. Space-based remote sensing techniques for measuring fAOD has been developed. For fAOD, Levy et al.(2010) reported that the fine-mode fraction (FMF) can be used to separate fine mode aerosols from coarse mode ones. But the MODIS L2 FMF is unfortunately unreliable over land, as has been shown in some studies (Levy et al.,2007; Levy et al., 2010; Bellouin et al., 2005). In addition, the temporal resolution of MODIS is low, it can not obtain the daily variation characteristics of the regional aerosol information. Therefore, the high temporal resolution satellites for fine mode aerosol study is very necessary. Recently, Himawari- 8 was launched on 7 October, 2014, it is Japan's new-generation geostationary meteorological satellite (Bessho et al., 2016). Himawari-8 has high temporal resolution $(10 \mathrm{~min})$ and can provide multiple observations for a single location, which makes it suitable for monitoring aerosol variations. Both MODIS and Himawari-8 release(offer) the fine mode aerosol products, but the validation of their aerosol products is mostly focused on AOD, for the fine mode aerosol product is limited (Yan et al., 2017a).

Therefore, in this study, we used the ground-based AERONET measurements over 22 Asian sites to validate the fine aerosol products for MODIS and Himawari-8.A comprehensive discussion of the differences and limitations between MODIS and Himawari- 8 fine mode aerosol products are also presented in this study.

\section{DATA AND METHODS}

\subsection{MODIS C6 MOD04 product}

The Medium Resolution Imaging Spectroradiometer (MODIS) carried on two satellites Terra and Aqua (launched in 1999 and 2002 respectively) is the key equipment of the National Aeronautics and Space Administration EOS (Earth Observing System) (Barnes, 2003). The latest version C006 was released in the 2014. Besides improving the original $10 \mathrm{~km}$ resolution products, it also announced a new $3 \mathrm{~km}$ product. Data can be obtained from LAADS DAAC (https://ladsweb.modaps.eosdis. nasa.gov). In this study, MODIS Collection 6 (C6) DT 
algorithm-based AOD (Aerosol_Optical_Depth_Land) and FMF (Optical_Depth_Ratio_Small_Land) products (MOD04) were used for comparisons with the observed values on the ground from January 2015 to December 2016.The purpose is to validate the accuracy of MODIS fine mode aerosol products.

\subsection{Himawari-8 satellite data}

Himawari-8 was launched by the Japanese Meteorological Agency (JMA) on October 7, 2014 and started running on July 7, 2015. It carries a Himawari imaging system (AHI) with high spectral, time and radiometric resolution. AHI has 16 visible and infrared channels. The spatial resolution is $0.5-2 \mathrm{~km}$ and the temporal resolution is 10 minutes (six full images per hour) (Lee et al., 2017; Yan et al., 2018). Data can be obtained from EORC (http://www.eorc.jaxa.jp/ptree). In this study, we used Himawari-8 Level 2 (Version 1.0) fine mode aerosol products "Optical Depth Ratio (fine)" with a spatial resolution of $5 \mathrm{~km}$ from July 2015 to December 2016 to validate it's accuracy.

\subsection{Aerosol Robotic Network (AERONET)}

The Aerosol Robotic Network (AERONET) is a worldwide network of calibrated ground-based Sun photometers which provides cloud screened and quality assured spectral AOD in the range of 0.340 to $1.060 \mu \mathrm{m}$ with low uncertainty (0.01-0.02) and high temporal resolution (every $15 \mathrm{~min}$ ). AERONET data can be obtained from the GSFC (https://aeronet.gsfc.nasa.gov/). 22 sites (Figure 1) which have long-term ground observations in Asia were selected in this study. We used AERONET Level 2.0 data which have completed cloud filtering and quality verification to validate MODIS and Himawari- 8 satellite fine mode aerosol products.

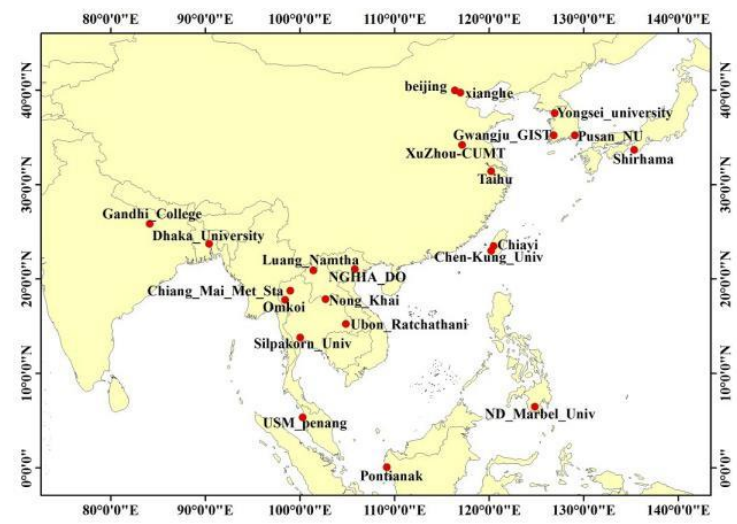

Figure 1. Geographical location of 22 sites in Asia

\subsection{Method}

This study used the fAOD and FMF from Himawari- 8 and MODIS aerosol products to compare them with the groundbased data of AERONET for the validation purpose $(0.5 \mathrm{~h}$ before and after satellite overpass). The accuracy is validated by standard error (RMSE), mean absolute error (MAE) and expected error (EE).

\section{RESULTS}

\subsection{The Validation of fAOD}

Figure 2 is a comparative validation diagram for fine mode aerosol products $\mathrm{FAOD}$ of MODIS (fAOD=AOD*FMF) and Himawari- 8 . The dotted line is $1: 1$ line and the real line is linear regression fitting curve. Model performance was assessed by determination coefficient $\left(\mathrm{R}^{2}\right)$, RMSE and MAE.
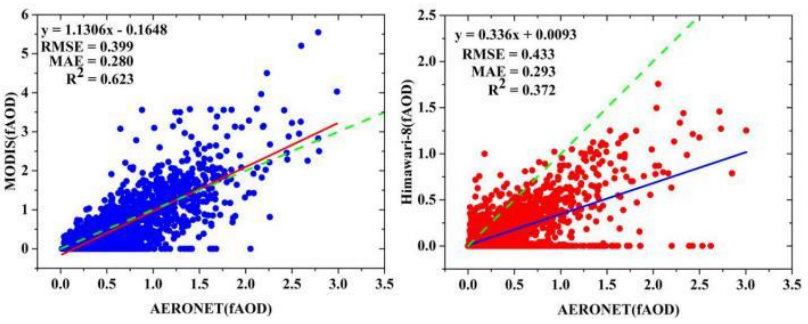

Figure 2. Validation of MODIS and Himawari-8 fAOD (500 nm) observations against AERONET measurements for the years of 2015-2016.

As shown in Figure 2, MODIS fAOD has a higher accuracy $\left(\mathrm{R}^{2}=0.623, \quad \mathrm{RMSE}=0.399, \quad \mathrm{MAE}=0.280\right)$ than that of the Himawari-8's $\left(\mathrm{R}^{2}=0.372\right.$, RMSE $=0.433$, MAE $\left.=0.293\right)$, which shows that the retrieval value of MODIS fAOD is more consistent with ground-based observations.

Figure 3 shows the validation result for the fAOD values by MODIS and Himawari-8. The EE envelope for fAOD is $\pm(0.05$ $+0.15 \times$ AERONET fAOD). In the validation of MODIS fAOD, $0-10 \%$ of the retrievals are falling within EE in four sites (Chen-Kung_Univ, Dhaka_University, Gwangju_GIST and Pusan_NU). However, a good accuracy is found in Beijing and Omkoi (40-50\% within EE). For the Himawari-8 fAOD, 0$10 \%$ of the retrievals are falling within $\mathrm{EE}$ in three sites (Dhaka_University, Gandhi_College and XuZhou) and 10-20\% of the retrievals are within $\mathrm{EE}$ in eight sites (Chiang_Mai_Met_Sta, Nong_Khai, Silpakorn_Univ, NGHIA_DO, Yongsei_university, Pusan_NU, Luang_Namtha and USM_penang). However, only in the Shirhama AERONET site, it has $40-50 \%$ of retrievals are falling within EE. In general, MODIS fAOD in most sites is better than that of Himawari-8's. However, in the comparison, we found that both MODIS and Himawari-8 fAOD are underestimated.

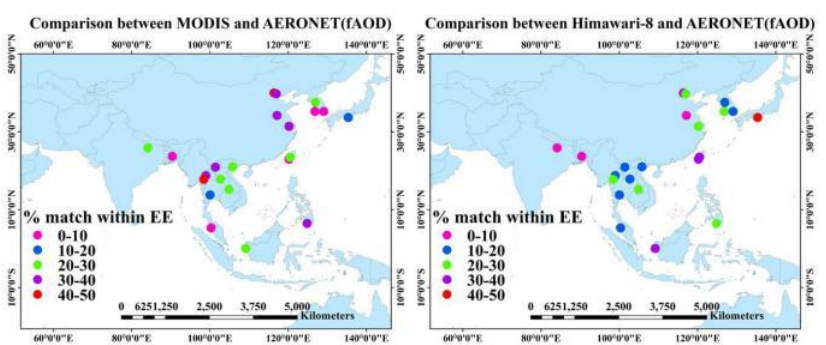

Figure 3.Validation of MODIS and Himawari-8 fAOD observations against AERONET measurements at 22 sites for the years of 2015-2016.

\subsection{The Validation of FMF}

Figure 4 shows the validation results for the MODIS and Himawari-8 FMF retrievals using AERONET data as the ground truth. From Figure 4, MODIS FMF also has a higher retrieval accuracy $(r=0.453$, RMSE $=0.520$, MAE $=0.433)$ compared with the Himawari-8 FMF $(r=0.219$, RMSE $=0.535$, $\mathrm{MAE}=0.438$ ) 

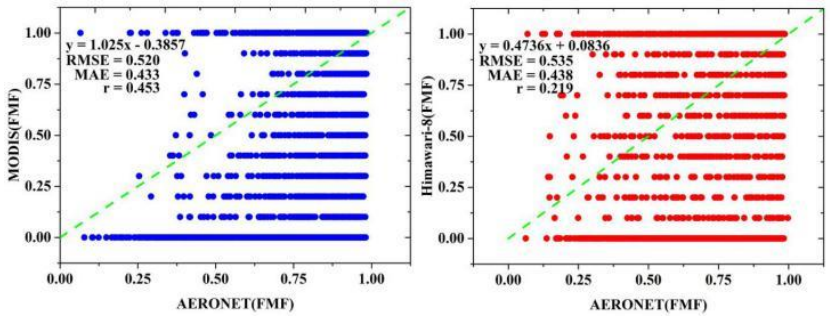

Figure 4. Validation of MODIS and Himawari-8 FMF against AERONET measurements for the years of 2015-2016.

Figure 5 shows the validation results for MODIS and Himawari-8 FMF in each AERONET site. The EE for the FMF is $\pm 15 \%$ of AERONET FMF. For the MODIS FMF, 0-20\% of retrievals falling within EE are found in most of sites, such as Beijing, Gwangju_GIST, Pusan_NU, Yongsei_university and Shirhama. The best accuracy is found in Luang_Namtha, Xianghe and Chiang_Mai_Met_Sta, which shows that 40-50\% of the retrievals are falling within EE. For the Himawari-8 FMF, the best accuracy is found in two sites, which are Luang_Namtha and Taihu (45-60\% within EE). However, as shown in Figure 5, the accuracy of Himawari-8 FMF is low in most of sites $(0-30 \%$ within EE). Furthermore, from the comparison, we found that both MODIS and Himawari-8 FMF are underestimated.

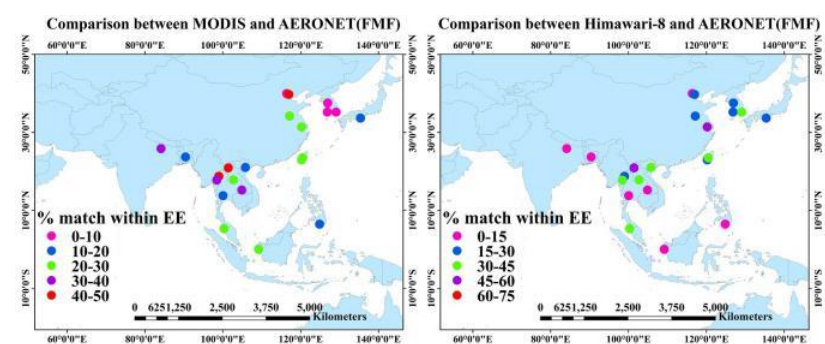

Figure 5.Validation of MODIS and Himawari-8 FMF observations against AERONET measurements at 22 sites for the years of 2015-2016.

\section{CONCLUSION}

Based on 2 years data (2015-2016) of 22 AERONET sites in Asia, this study validated the fine mode aerosol products for MODIS and Himawari-8. In the validation of all AERONET data, the accuracy of MODIS fAOD (RMSE is 0.399 and MAE is 0.280 ) and FMF (RMSE is 0.520 and MAE is 0.433) are higher than that of the Himawari-8 fAOD (RMSE is 0.433 and MAE is 0.293 ) and FMF (RMSE is 0.535 and MAE is 0.438). For the validation in different locations, 40 50\% of MODIS fAOD falling in EE at Beijing and Omkoi sites. But its accuracy is poor $(\mathrm{EE} \%=0 \sim 10 \%)$ at Gwangju_GIST, Pusan_NU, ChenKung_Univ and Dhaka_University sites. For the Himawari-8 fAOD, $40 \sim 50 \%$ of the retrievals falling in EE at at Shirhama site. But its accuracy is poor $(\mathrm{EE} \%=0 \sim 10 \%)$ at Dhaka_University,Gandhi_College and XuZhou-CUMT sites. As for the FMF derived by MODIS and Himawari-8, this research shows that they are all highly uncertain. This study also found that fAOD and FMF in MODIS and Himawari- 8 are all underestimated comparing with the AERONET measurements. Thus, it is necessary to further develop the new algorithm to improve the accuracy and applicability of satellitebased of fine mode aerosol products.

\section{ACKNOWLEDGEMENTS}

This work was supported by This work was supported by the National Key Research and Development Plan of China (2017YFC1501702) and the Fundamental Research Funds for the Central Universities.

\section{REFERENCES}

Barnes, W. L., Xiong, X., \& Salomonson, V. V. 2003. Status of terra modis and aqua modis. Advances in Space Research, 32(11), 2099-2106.

Bellouin, N., Boucher, O., Haywood, J., \& Reddy, M. S. 2005. Global estimate of aerosol direct radiative forcing from satellite measurements. Nature, 438.

Bessho, K., Date, K., Hayashi, M., Ikeda, A., Imai, T., \& Inoue, H., et al. 2016. An introduction to himawari-8/9- japan's newgeneration geostationary meteorological satellites.Journal of the Meteorological Society of Japan.ser.ii, 94.

Holben, B. N., Eck, T. F., Slutsker, I., Tanré, D., Buis, J. P., \& Setzer, A., et al. 1998. Aeronet-a federated instrument network and data archive for aerosol characterization.Remote Sensing of Environment,66, 1-16.

Lee, S., Han, H., Im, J., Jang, E., \& Lee, M. I. (2017). Detection of deterministic and probabilistic convection initiation using Himawari-8 Advanced Himawari Imager data. Atmospheric Measurement Techniques, 10(5).

Levy, R. C., \& Remer, L. A. 2007. Second generation operational algorithm: retrieval of aerosol proerties over land from inversion of modis spectral reflectance. Journal of Geophysical Research,112(D13).

Levy, R. C., Remer, L. A., Kleidman, R. G., \& Mattoo, S. 2010. Global evaluation of the collection 5 modis dark-target aerosol products over land. Atmospheric Chemistry and Physics, 10(21), 10399-10420.

Yan, X., Li, Z., Luo, N., Shi, W., Zhao, W., Yang, X., \& Jin, J. (2018). A minimum albedo aerosol retrieval method for the new-generation geostationary meteorological satellite Himawari-8. Atmospheric Research, 207, 14-27.

Yan, X., Li, Z., Shi, W., Luo, N., Wu, T., \& Zhao, W. (2017a). An improved algorithm for retrieving the fine-mode fraction of aerosol optical thickness, part 1: Algorithm development. Remote Sensing of Environment, 192, 87-97.

Yan, X., Shi, W., Li, Z., Li, Z., Luo, N., Zhao, W., Wang, H., \& Yu, X. (2017b). Satellite-based PM2.5 estimation using finemode aerosol optical thickness over China. Atmospheric Environment, 170, 290-302.

Yumimoto, K., Nagao, T. M., Kikuchi, M., Sekiyama, T. T., Murakami, H., \& Tanaka, T. Y., et al.2016. Aerosol data assimilation using data from himawari-8, a next-generation geostationary meteorological satellite. Geophysical Research Letters, 43(11). 